\title{
Correlation between conventional disease activity measures in juvenile chronic arthritis
}

\author{
Angelo Ravelli, Stefania Viola, Nicolino Ruperto, Barbara Corsi, Giuseppina Ballardini, \\ Alberto Martini
}

\begin{abstract}
Objective-To estimate in a cross sectional analysis the degree of colinearity among the disease activity measures more commonly used in juvenile chronic arthritis (JCA).

Methods-This study assessed in a single clinical evaluation three subjective variables, three measures of functional capacity, eight articular indices, and two laboratory indicators of systemic inflammation in 55 consecutive children with JCA. The relation between the clinical measures of JCA activity was determined by Pearson correlation coefficients. An $r$ value of 0.7 or greater was considered evidence of colinearity.

Results-Among the subjective variables, parent global assessment of overall well being and parent assessment of pain were correlated with each other; the physician assessment of disease activity did not show evidence of colinearity with any other variable. The functional status measures were correlated with each other, but not with the indices of articular inflammation. There was a high degree of colinearity among the articular variables, with the number of active joints and the overall severity score being correlated with each other as well as with all the single articular indices. The laboratory variables were correlated with each other, but not with any of the articular, functional or subjective variables.

Conclusion-Our results show a high degree of colinearity among the disease activity measures belonging to the same category, whereas this is uncommon for variables that investigate different domains of disease activity. These data underline the need to include the evaluation of each domain in the assessment of JCA activity.
\end{abstract}

(Ann Rheum Dis 1997;56:197-200)

Clinical assessment of disease activity in juvenile chronic arthritis (JCA) is commonly based on a multitude of measures, ranging from the parent/patient report of symptoms, to the extent and severity of synovitis on examination, to laboratory indicators of inflammation. Although the use of a number of different clinical measures permits a more exhaustive assessment of arthritis activity, it may also cause several problems. In clinical practice, it is time consuming and may be a source of disagreement among physicians. ${ }^{1}$ In clinical trials, the use of multiple endpoints can confuse interpretation of results and increase the risk of statistical errors. ${ }^{2}$ A large degree of redundancy among changes from baseline values in articular response variables has been shown. ${ }^{34}$

The purpose of this study was to evaluate in a cross sectional analysis the degree of colinearity among a large set of disease activity measures traditionally used in JCA.

\section{Patients and methods}

PATIENT SELECTION

Fifty five consecutive patients with JCA according to the EULAR criteria ${ }^{5}$ who were seen at the rheumatology unit of the Department of Pediatrics of the University of Pavia between September 1995 and May 1996 were enrolled in the study. To be included, patients had to have active arthritis in at least one joint. Active arthritis is defined as swelling or, if no swelling was present, limitation of movement with either pain upon movement or tenderness. There were 24 boys and 31 girls, aged 2.3 to 21.3 years (mean 10.5 ). The duration of JCA ranged from 3 to 210 months (mean 51.8). The age at onset of the eight patients over 16 years ranged from 2.3 to 15.5 years. The JCA onset subtype was systemic in 20 patients (all but one with polyarticular involvement), polyarticular in 16 patients (all rheumatoid factor negative), and pauciarticular in 19 patients (14 with polyarticular course).

\section{CLINICAL ASSESSMENT}

The following clinical measures of JCA activity were assessed in each patient. All assessments on individual patients were made once, at the same time, by the same observer (AR or SV).

\section{Subjective variables}

Physician global assessment of overall disease activity measured on a 5 point categorical scale ( 1 none, 2 mild, 3 moderate, 4 severe, 5 very severe); parent global assessment of overall well being measured on an anchored horizontal 15 $\mathrm{cm}$ visual analogue scale, with 'very well' at one end (scored 0) and 'very poor' at the other end (scored 100); parent assessment of pain in the past week measured on an anchored horizontal $15 \mathrm{~cm}$ visual analogue scale, with 'no pain' at one end (scored 0) and 'very severe pain' at the other end (scored 100). Both global assessment of overall well being and assessment of pain were done by a parent for all patients. The distance from 0 to the

\author{
Accepted for publication \\ 13 December 1996 \\ Correspondence to: \\ Clinica Pediatrica \\ dell'Universita',IRCCS S \\ Matteo,P le Golgi, 2, 27100 \\ dell'Universita',
IRCCS Policlinico "S \\ Matteo"' \\ S Viola \\ B Corsi \\ G Ballardini
}


respondent's mark in the last two scales was measured using a metric rule. For purposes of analysis and in keeping with convention established by other studies that have used visual analogue scales, ${ }^{6}$ all measures were converted to a 0 to 3 score ( 0 best, 3 worst) by multiplying each value by 0.2 .

\section{Measures of functional capacity}

Modified Lee index (13 best, 39 worst) ${ }^{7}$; briefly, this index measures the child's performance of 13 daily activities; the ability of the child to perform each task is scored from 1 to 3 (1=yes, with no difficulty; $2=y e s$, but with difficulty due to pain or stiffness; $3=$ no, unable to perform task); Juvenile Arthritis Functional Assessment Report (JAFAR) (0 best, 46 worst $)^{8}$; Childhood Health Assessment Questionnaire (CHAQ) disability index (0 best, 3 worst). ${ }^{9}$ The first two functional measures were completed by the physician by asking a parent the questions. The Italian version of the $\mathrm{CHAQ}^{10}$ was completed by a parent. Children aged less than 6 years were excluded from the evaluation of the modified Lee index and the JAFAR because these functional measures do not enable assessment in younger children. ${ }^{78}$

\section{Articular variables}

The following articular indices were assessed in a total of 64 joints (those joints that are included in the normal clinical evaluation): number of joints with pain on motion/ tenderness; pain on motion/tenderness score (graded as $0=$ none; $1=$ mild, patient complains on joint movement or palpation; $2=$ moderate, patient withdraws or changes facial expression on movement or palpation; $3=$ severe, patient responds severely to movement or palpation); number of swollen joints; swelling score (graded as $0=$ none; $1=$ mild, definite swelling but with no blurring of normal skeletal outlines; $2=$ moderate, definite obscuring of skeletal landmarks; 3=severe, no discernible skeletal landmarks); number of joints with limited range of motion; limited range of motion score (graded as $0=$ full range; $1=1$ to $25 \%$ limitation; $2=26$ to $50 \%$ limitation; $3=51$ to $75 \%$ limitation; $4=76$ to $100 \%$ limitation). In addition to these indices, the following variables were calculated and recorded: total number of joints with active arthritis (defined as above); overall severity score, calculated as the sum of the severity ratings obtained for the scores of pain on motion/tenderness, swelling, and limited range of motion.

\section{Laboratory variables}

Erythrocyte sedimentation rate (Westergren method); C reactive protein (nephelometry).

\section{STATISTICAL ANALYSIS}

The relation between the clinical measures of JCA activity was evaluated by determining Pearson correlation coefficients ( $r$ value). Evidence of colinearity was considered to be present if the $r$ value was $\geq 0.7$. Regression analysis was carried out using the Pearson correlation function for Excel, Version 5.0 (Microsoft Corporation).

\section{Results}

Values for all variables were available for all patients, with the exception of the JAFAR and modified Lee index, for which there were 11 missing values (patients aged less than 6 years)

Table 1 shows the $r$ values for all correlations included in the analysis. Among the subjective variables, only parent global assessment of overall well being and parent assessment of pain showed colinearity. Subjective variables did not show evidence of colinearity with any

Table 1 Pearson product moment correlation coefficient for the 55 patients with $\mathcal{F C A}$

\begin{tabular}{|c|c|c|c|c|c|c|c|c|c|c|c|c|c|c|c|}
\hline & $\begin{array}{l}M D \\
\text { global }\end{array}$ & $\begin{array}{l}P r \\
\text { global }\end{array}$ & $\begin{array}{l}\text { Pr } \\
\text { pain }\end{array}$ & $\begin{array}{l}\text { Modif } \\
\text { LEE }\end{array}$ & FAFAR & $C H A Q$ & $\begin{array}{l}\text { No of } \\
\text { joints } \\
\text { with } \\
\text { POMT }\end{array}$ & $\begin{array}{l}\text { POMT } \\
\text { score }\end{array}$ & $\begin{array}{l}\text { No of } \\
\text { swollen } \\
\text { joints }\end{array}$ & $\begin{array}{l}\text { Swelling } \\
\text { score }\end{array}$ & $\begin{array}{l}\text { No of } \\
\text { joints } \\
\text { with } \\
\text { LROM }\end{array}$ & $\begin{array}{l}\text { Score } \\
\text { joint } \\
\text { with } \\
\text { LROM }\end{array}$ & $\begin{array}{l}\text { No of } \\
\text { active } \\
\text { joints }\end{array}$ & $\begin{array}{l}\text { Overall } \\
\text { severity } \\
\text { score }\end{array}$ & $E S R$ \\
\hline Pr global & 0.53 & & & & & & & & & & & & & & \\
\hline Pr Pain & 0.60 & 0.73 & & & & & & & & & & & & & \\
\hline Modified-LEE & 0.55 & 0.58 & 0.61 & & & & & & & & & & & & \\
\hline JAFAR & 0.47 & 0.52 & 0.51 & 0.95 & & & & & & & & & & & \\
\hline CHAQ & 0.47 & 0.52 & 0.46 & 0.89 & 0.90 & & & & & & & & & & \\
\hline $\begin{array}{l}\text { No of joints with } \\
\text { POMT }\end{array}$ & 0.58 & 0.38 & 0.39 & $\overline{0.46}$ & $\overline{0.45}$ & 0.42 & & & & & & & & & \\
\hline POMT score & 0.57 & 0.40 & 0.41 & 0.50 & 0.50 & 0.41 & $\underline{0.98}$ & & & & & & & & \\
\hline No of swollen joints & 0.53 & 0.25 & 0.17 & 0.47 & 0.50 & 0.46 & $\overline{0.59}$ & 0.60 & & & & & & & \\
\hline Swelling score & 0.60 & 0.29 & 0.21 & 0.50 & 0.51 & 0.47 & 0.57 & 0.58 & 0.98 & & & & & & \\
\hline $\begin{array}{l}\text { No of joints with } \\
\text { LROM }\end{array}$ & 0.39 & 0.28 & 0.25 & 0.52 & 0.52 & 0.50 & 0.81 & $\underline{0.79}$ & $\overline{0.59}$ & 0.54 & & & & & \\
\hline $\begin{array}{l}\text { Score joint with } \\
\text { LROM }\end{array}$ & 0.34 & 0.26 & 0.25 & 0.62 & 0.61 & 0.52 & 0.69 & 0.70 & 0.49 & 0.46 & $\underline{0.95}$ & & & & \\
\hline No of active joints & 0.55 & 0.30 & 0.26 & 0.49 & 0.52 & 0.46 & 0.87 & 0.86 & 0.88 & 0.85 & 0.82 & 0.70 & & & \\
\hline $\begin{array}{l}\text { Overall severity } \\
\text { score }\end{array}$ & 0.55 & 0.37 & 0.35 & 0.66 & 0.65 & 0.56 & $\overline{0.88}$ & $\overline{0.90}$ & $\overline{0.72}$ & $\overline{0.70}$ & $\overline{0.94}$ & $\overline{0.91}$ & 0.90 & & \\
\hline ESR & 0.54 & 0.39 & 0.31 & 0.35 & 0.27 & 0.29 & 0.29 & 0.30 & 0.28 & 0.31 & 0.29 & 0.30 & 0.23 & 0.35 & \\
\hline CRP & 0.38 & 0.25 & 0.17 & 0.06 & -0.01 & 0.07 & 0.20 & 0.17 & 0.17 & 0.22 & 0.11 & 0.06 & 0.13 & 0.15 & 0.74 \\
\hline
\end{tabular}

An $r$ value $\geq 0.7$ (bold and underlined) was considered to indicate colinearity. Pr: parent; JAFAR: Juvenile Arthritis Functional Assessment Report; CHAQ: Childhood Health Assessment Questionaire; POMT: pain on motion/tenderness; LROM: limited range of motion; ESR: erythrocyte sedimentation rate; CRP: C reactive protein. 
articular variable or functional measure. The functional status measures were correlated with each other, but did not show evidence of colinearity with any articular variable. The number of joints with pain/tenderness, swelling and limited range of motion was highly correlated with its respective severity score. The articular indices related to the assessment of pain/tenderness and range of motion were correlated with each other, but not with those related to the assessment of swelling. The number of active joints and the overall severity score were correlated with each other as well as with all the single articular indices. The laboratory variables were correlated with each other, but not with any of the articular, functional or subjective variables. Patient age and disease duration were not correlated with any other variable (data not shown).

\section{Discussion}

We investigated in a cross sectional analysis the degree of correlation between the measures more commonly used to assess the disease activity in children with JCA. These variables were grouped in four categories, each related to a different domain of disease activity: subjective variables, measures of functional capacity, articular indices, and laboratory parameters. Our results show that colinearity is frequently seen within each category, but is uncommon among variables of different categories.

Among subjective variables, parent global assessment of overall well being and parent assessment of pain were correlated with each other, suggesting a great importance of the level of pain in the perception of well being or a simple 'drag effect' because the two visual analogue scales are located closely at the end of the CHAQ. The lack of colinearity among the physician assessment of disease activity and the other variables may reflect a judgement based more on a global clinical impression than on single disease activity features.

There was a high colinearity among the functional status measures specifically developed for use in children with JCA, including the CHAQ, the JAFAR and the modified Lee index. This finding shows that the assessment of functional disability gives similar results either when the questionnaires are completed by the physician by asking a parent (JAFAR, modified Lee Index) or by the parent himself (CHAQ). However, a substantial proportion of patients was missed from this analysis because both the JAFAR and the modified Lee index do not enable a reliable functional assessment in younger children. ${ }^{78}$

The number of active joints and the overall severity score were highly correlated with each other and with all the other articular variables, suggesting that each of these global indices would yield the same clinical information and that the use of their components could be avoided without loss of relevant data.

The two laboratory indicators of inflammation were also correlated, but did not show colinearity with any other disease activity variable.
As this study was based on single assessments of patients at one point in time, we did not obtain information on the redundancy of these variables in a clinical trial in which the correlation in change can be assessed. Indeed, the fact that two (or more) variables show colinearity in a cross sectional analysis does not mean that they will be redundant in a clinical trial, unless their sensitivity to change is quite similar. Because the sensitivity to change of the different endpoints is known to be variable, it is expected that delta values will show less correlation than cross sectional analyses. Moreover, as all but six of the 55 patients had polyarticular involvement, our findings, particularly those concerning functional capacity and articular variables, are only of value for patients with a polyarticular course of JCA.

In conclusion, the results of this cross sectional study show that among the variables commonly used to assess the disease activity in JCA there is a large degree of colinearity between those belonging to the same category. This is uncommon, however, for variables that measure different domains of disease activity. These data underline the need to include the evaluation of each domain in the assessment of JCA activity and support the validity of the 'preliminary core set of outcome measures' for use in JCA clinical trials, which was established through an international project. ${ }^{11}$ The core set includes the following variables: (1) physician global assessment of disease activity; (2) parent/patient global assessment of overall well being; (3) functional ability; (4) number of joints with active arthritis; (5) number of joints with limited range of motion; (6) erythrocyte sedimentation rate. Using this core set, a 'preliminary definition of improvement' in JCA was recently developed through an international consensus conference. ${ }^{12}$

This work was supported by the IRCCS Policlinico 'S Matteo', Pavia, Italy. We thank Dr Edward H Giannini (Cincinnati, USA) for his review of the manuscript.

1 Giannini EH, Lovell DJ. Inter physician reliability estimates or conventional disease activity measures in JRA. (Abstract). Arthritis Rheum 1994;37(Suppl):S328.

2 Felson DT. Choosing a core set of disease activity measures for rheumatoid arthritis clinical trials. J Rheumatol 1993;20:531-4

3 Anderson JJ, Felson DT, Meenan RF, Williams HJ. Which traditional measures should be used in rheumatoid arthritis clinical trials? Arthritis Rheum 1989:32:1093-9.

4 Ruperto N, Giannini EH. Redundancy of conventional articular response variables used in juvenile chronic arthriarticular response variables used in juvenile chro
tis clinical trials. Ann Rheum Dis 1996;55:73-5.

5 Wood P. Special meeting on: nomenclature and classification of arthritis in children. In:Munthe E, ed. The care of tion of arthritis in children. In:Munthe E, ed. The care of
rheumatic children. Basle: EULAR Publishers, 1987: 47-50.

6 Ruperto N, Levinson JE, Ravelli A, Shear ES, Tague BL, Murray K, et al. Long-term health outcomes and quality of life in American and Italian inception cohorts of patients with juvenile rheumatoid arthritis. I. Outcome status. J Rheumatol (in press)

7 Ravelli A, Viola S, Ramenghi B, Di Fuccia G, Ruperto N, Zonta L, et al. Evaluation of response to methotrexate by a functional index in juvenile chronic arthritis. Clin Rheumatol 1995; 14:322-6.

8 Howe S, Levinson J, Shear E, Hartner S, McGirr G, Schulte $\mathrm{M}$, et al. Development of a disability measurement tool for juvenile rheumatoid arthritis. The Juvenile Arthritis Functional Assessment Report for Children and Their Parents. Arthritis Rheum 1991;34:873-80.

9 Singh G, Athreya BH, Fries JF, Goldsmith DP. Measurement of health status in children with juvenile rheumatoid ment of health status in children with juven

10 Fantini F, Corvaglia G, Bergomi P, Gattinara M, Gerloni V, Lomater C, et al. Validation of the Italian version of the 
Stanford Childhood Health Assessment Questionnaire for measuring functional status in children with chronic arthritis. Clin Exp Rheumatol 1995;13:785-91.

11 Giannini EH, Lovell DJ, Felson DT, Goldsmith CH. Preliminary core set of outcome variables for use in JRA clinical trials. [Abstract]. Arthritis Rheum 1994; 37(suppl):S428.

2 Giannini EH, Ruperto N, Ravelli A, Lovell DJ, Felson DT,

Martini A. Preliminary definition of improvement in juvenile arthritis. Arthritis Rheum (in press).

$\sum_{\bar{O}}$

융

Nิ 